\title{
Improvement Properties of the Cutting Tools Using Technical Plasma Treatment
}

\author{
Ferkous Embarek ${ }^{1}$, Amara Idriss ${ }^{1}$, Djeribaa Abdeldjalil ${ }^{1}$, Boughouas Hamlaoui ${ }^{1}$, Achour Slimane ${ }^{2}$ \\ ${ }^{1}$ Engineering Mechanical Department, Engineering Sciences Faculty, University of Constantine, Algeria; ${ }^{2}$ Research Unit in Materials \\ Physics and Applications, University of Constantine, Algeria. \\ Email: ferkousembarek@yahoo.fr
}

Received May $31^{\text {st }}, 2011$; revised June $27^{\text {th }}, 2011$; accepted July $10^{\text {th }}, 2011$.

\begin{abstract}
In spite of the considerable progress made in the domain of the sciences of materials, cutting tools subjected to an intense abrasive wear and a very high temperature of edge. They record during their use a reduced working life. The operations of machining on lathe are regularly stopped for replacing these tools, which influences enormously the production process. Indeed, the search the new materials of substitution, remain a domain very coveted, owing to the fact, it belongs to one stake very significant industrial, in particular, in the mechanical domain and its varied sectors. The recourse to the thermal treatments traditional, limiting in an interval, reduces the wear and the excessive consumption of these cutting tools, but the principal concern of the experts and researchers, in the domain of the mechanical engineering, remain posed. The goal of this study is the introduction of the technique of plasmas, as physical phenomenon, for making material of coating at base of titanium nitrides doped at iron, at the different concentrations. To this objective, one magnetron sputtering with plasma was used for the realization of the coatings deposed on the active parts of the cutting tools. During the experimentation, it was noted that the cutting tools which are treated by plasma, subjected to the machining operations on lathe and the hardness tests, presents one improvement of their hardness and a remarkable increase in their lifespan.
\end{abstract}

Keywords: Cutting Tools, Plasma, Nitride, Titanium, Doping, Target, Hardness

\section{Introduction}

The application of techniques of plasma like physical phenomena in the development of new materials of substitution, allowing the improvement arouses as well a keen interest with the meadows of the scientific community as to the meadows of industrial circle [1-6]. Indeed, the mechanisms intervening in the formation of a new material from a target by ejection of the particles are very complex [1,2,7-11]. The growth of the deposit, the quantity of the species entering concerned, the reactions controlling remain still known badly [7]. In order to improve the mechanical properties of the cutting tools, namely the hardness, the wear resistance and in particular their lifespan, we called upon the technique of plasmas, physical phenomenon in the domain of mechanics, for the development of the layers of titanium nitride doped out of iron, like new material of coating of the active part of the cutting tools. Cutting tools have attracted a lot of interest over past decade, and a recent review [8] discusses a number of experimental, analytical and numerical studies.

F. Kieckow [9], has studied the adhesion improvement produced by bright plasma nitriding hardening of tool steel prior to TiN deposition was investigated by angleresolved X-ray photoelectron spectroscopy and atomic profiling with sub-nanometric depth resolution. Besides hardening, analysis of the O1s, N1s, Ti2p, Fe2p, and Cr2p photoelectron groups showed that the finely dispersed chromium and iron nitrides produced by plasma nitriding also replace in part the oxides and hydroxides in the near-surface regions. Thus, the enhanced adhesion and improved performance observed in duplex treated tool steel are discussed in light of the present findings: 1) stronger chemical bonding at the coating/substrate interface promoted by bright plasma nitriding of the steel substrate prior to TiN deposition; and 2) enhanced inter-diffusion around the coating/substrate interface owing to the removal of the oxides which constitute diffusion barriers, producing an enlarged contact area and more gradual coating/substrate interfaces. 
More recently S. Cardinal et al. [10] developed materials with both a good hardness and a good toughness. He investigates the effect of TiN addition and binder content on the microstructure and the properties of the $\mathrm{TiC}$ based cermets elaborated by pressure less sintering. Results have showed that dense cermets with specific core/rim structure have been obtained. The rupture strength and the toughness increase with the addition of Ni. The optimum values of mechanical properties were found for the cermets with $15 \mathrm{wt} \% \mathrm{Ni}$ and $10 \mathrm{wt} \%$ TiN additions, respectively, which exhibit a vickers hardness over $1400 \mathrm{Hv}$ and a fracture toughness around 13.6 MP. B. Subramanian et al. [11], investigated thin films of titanium nitride (TiN), he was prepared on mild steel (MS) by a physical vapor deposition (PVD) method namely direct current reactive magnetron sputtering. With the aim of improving the adhesion of TiN layer an additional Nickel interlayer was brush plated on the steel substrates prior to TiN film formation.

The phase has been identified with X-ray diffraction (XRD) analysis, and the results show that the prominent peaks observed in the diffraction patterns correspond to the $\left(\begin{array}{lll}1 & 1 & 1\end{array}\right),\left(\begin{array}{lll}2 & 0 & 0\end{array}\right)$ and $\left(\begin{array}{lll}2 & 2 & 2\end{array}\right)$ planes of TiN. Cross-sectional SEM indicated the presence of dense columnar structure. The mechanical properties (modulus and hardness) of these films were characterized by nano-indentation. Ti-Al-Si-N films deposited on WC-Co substrates by a hybrid coating system was studied by Y. K. Jeong et al. [1]. The synthesized Ti-Al-Si-N films were revealed to be composites of solid-solution $(\mathrm{Ti}, \mathrm{Al}, \mathrm{Si}) \mathrm{N}$ crystallites and amorphous $\mathrm{Si}_{3} \mathrm{~N}_{4}$ by instrumental analyses such as XRD and HRTEM. The highest micro-hard- ness value $(50 \mathrm{GPa})$ was obtained from the Ti-Al-Si-N film having the $\mathrm{Si}$ content of 9 at \%, the microstructure of which was characterized by a nano-composite of nc-( $\mathrm{Ti}$, $\mathrm{Al}, \mathrm{Si}) \mathrm{N} / \mathrm{a}-\mathrm{Si}_{3} \mathrm{~N}_{4}$.

The tool lives of Ti-Al-Si-N coated tool for AISI D2 steel of hardness 62 HRC were studied under various cutting speeds in high speed machining center. Tool wear curves with cutting length were presented.

A. Ebrahimi et al. [2] also investigated the machinability of micro-alloyed steel (30 MnVS6) and quenchedtempered (QT) steels (AISI 1045 and AISI 5140), at different cutting condition. An experimental investigation was conducted to determine the effects of cutting speed, feed rate, hardness, and work piece material on the flank wear land and tool life of coated cemented carbide inserts in the hard turning process. Chips characteristics and chip/tool contact length were also investigated. The different sections (shear plane, micro crack, thickness and edge) of the chip were examined by scanning electron microscope (SEM). The results showed that the tool life and machinability of the micro-alloyed steel is better than the QT steels at identical cutting condition.

Experimentally, the behavior of a CBN tool during hard turning of $100 \mathrm{Cr}_{6}$-tempered steel have been studied by $\mathrm{M}$. A. Yallese et al. [3]. Initially, a series of long-duration wear tests is planned to elucidate the cutting speed effects on the various tool wear forms. Then, a second set of experiments is devoted to the study of surface roughness, cutting forces and temperature changes in both the chip and the work-piece. The results show that CBN tool offers a good wear resistance despite the aggressiveness of the $100 \mathrm{Cr}_{6}$ at $60 \mathrm{HRC}$. The optimal productivity of machined chip was recorded at a speed of $120 \mathrm{~m} / \mathrm{min}$ for an acceptable tool flank wear below $0.4 \mathrm{~mm}$. Beyond this limiting speed, roughness (Ra) is stabilized because of a reduction in the cutting forces at high speeds leading to a stability of the machining system. Surface quality obtained with CBN tool significantly compared with that of grinding despite an increase in the advance by a factor of 2.5. A relationship between flank wear $(\mathrm{Vb})$ and roughness $(\mathrm{Ra})$ is deduced from parametric analysis based on extensive experimental data.

In the present paper, experiment work is reported. This work relates to the study of the improvement of the mechanical properties of the cutting tools on which deposits of titanium nitride doped with iron $(0.7 \%, 1.4 \%, 2 \%, 1 \%$, $2.8 \%, 3.5 \%$ ) were carried. After experimentation, the results obtained showed a remarkable increase in hardness in an interval of doping out of suitable iron (2.1\%) [4]. The cutting tools covered with doped layers with the iron, subjected to the machine-works on lathe, according to the model of Taylor, records an improvement of the lifespan, expressed by a bending of the curves $\mathrm{Vb}=\mathrm{f}(\mathrm{T})$ towards the line, on low the, average ones and high cutting speeds.

\section{Technique of Development}

The basic technique consists at the use of a magnetron sputtering at plasma whose principle of working (high vacuum, high voltage, proportions of gases of starting of plasma), enable to make a material of titanium nitride doped of iron, starting from one target of titanium, strewn by small pure iron targets. The layers deposited are initially intended to wrap the active part of the cutting tools.

\subsection{Target Preparation}

To obtain the layers of TiN doped in iron, the preparation of material to depose must be in the form of a target. For our case, we have produced one target interchangeable of titanium, shown in Figure 1 in circular form, with $5 \mathrm{~cm}$ in diameter and $0.3 \mathrm{~cm}$ for thickness.

For allow obtaining doping, this target was strewn by small targets (5 $\mathrm{mm}$ of diameter and $1 \mathrm{~mm}$ thickness) of pure iron. The components ratio (\%) TiN-Iron is a function of the surfaces exposed to plasma and the output of 


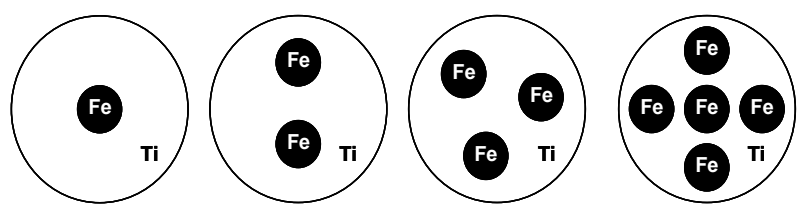

Figure 1. The configuration of titanium and iron superposed targets.

pulverization of each material. The number of secondary targets is given according to $\%$ of doping of iron.

\subsection{Coatings Development}

The development of these layers of titanium nitride doped with iron on the cutting tools is carried in accordance with the usual process [5]. After the preparation of the sputtering magnetron with plasma and the adjustment of the various parameters (distance inter-electrodes, selection of the high vacuum of work, the high voltage) and the preparation of the samples (cutting tools), and their installation on the door substrate, in the enclosure of the engine, the system of coatings of the cutting tools by deposition is engaged. The duration of the deposition, is function of the layer thickness to obtaining.

\subsection{Experimental Devices}

These deposits of titanium nitride doped with iron, were realized in the enclosed of the sputtering magnetron with plasma, show in Figure 2, realized previously—pregnant of work.

\subsection{Layers Disposition}

After one scouring of the target by a flow of bombardment, the protective shield of the target is actuated, and the operation of deposition of the layers of titanium nitride doped with iron starts under the conditions and the parameters of calibration of the starting of plasma.

Coatings of $(\mathrm{Ti}, \mathrm{Fe}) \mathrm{N}$ were deposited using a reactive magnetron sputter system. Two superposed cathodes (Titanium and Iron) were used. Iron concentration was varied by changing the cathode surface ratio-unbiased tools, and $\mathrm{NaCl}$ substrates were employed. The deposition conditions were: basic pressure $=10^{-5} \mathrm{mbar}$, total pressure $=10^{-2} \mathrm{mbar}$, nitrogen partial pressure $=5 \times 10^{-3} \mathrm{mbar}$, target to substrate distance $20 \mathrm{~cm}, \mathrm{DC}$ magnetron power = $200 \mathrm{~W} / \mathrm{cm}^{2}$. The deposition rate was $10 \mathrm{um} / \mathrm{h}$. The microstructure of coatings deposed on $\mathrm{NaCl}$ was observed in transmission electron microscope. The organization of the various series of deposition of the layers of coating is as follows, in Table 1.

\section{Experimentation of Cutting Tools Obtained}

Once covered by the layer of titanium nitride doped in

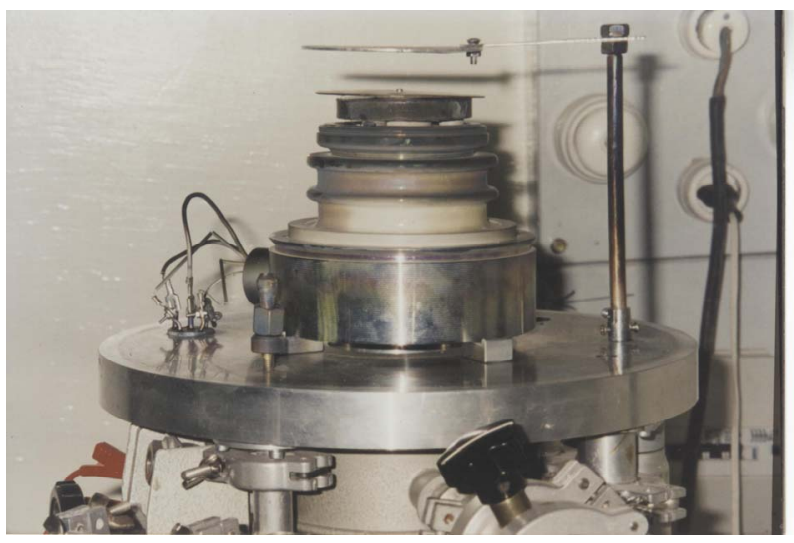

Figure 2. Together substrate of the sputtering.

Table 1. Series of cutting tools treatment.

\begin{tabular}{cl}
\hline Series & \multicolumn{1}{c}{ Substrates used in this study } \\
\hline $1^{\text {st }}$ series & 05 cutting tools without treatment \\
& 05 cutting tools to $0.7 \%$ iron \\
& 01 substrate $\mathrm{NaCl}$ \\
$2^{\text {nd }}$ series & 05 cutting tools to $1.4 \%$ iron \\
& 01 substrate $\mathrm{NaCl}$ \\
$3^{\text {rd }}$ series & 05 cutting tools to $2.1 \%$ iron \\
& 01 substrate $\mathrm{NaCl}$ \\
$4^{\text {th }}$ series & 05 cutting tools to $2.8 \%$ iron \\
& 01 substrate $\mathrm{NaCl}$ \\
$5^{\text {th }}$ series & 05 cutting tools to $3.5 \%$ iron \\
& 01 substrate $\mathrm{NaCl}$ \\
\hline
\end{tabular}

iron for the different concentrations $(0.7 \%, 1.4 \%, 2.1 \%$, $2.8 \%$ and $3.5 \%$ ), the cutting tools was subjected to the tests determination of hardness and the machining operations on lathe EMCO. A beach of selection cutting speeds without lubrication was adopted.

Compared to the use of the ordinary cutting tools, we recorded a net improvement of the principal mechanical properties of these tools.

\section{Results and Discussion}

After experimentation of the cutting tools whose the active parts were covered by this material with various percentages of doping of iron, the results obtained, made it possible, to release from the broad point of view the study for certain parameters characteristic, as for the performances of the cutting tools. Among the required main mechanical properties in mechanical engineering, the hardness, the characteristic of the tribological contact tool of cutting-piece to be machined and its wear resistance under the cutting pressure. This significant characteristic results in defining, in a direct way to the determination of the endurance and the lifespan of the cutting tool. 


\subsection{Evaluation of Hardness Obtained}

The micro-hardness (Hv) was determined using a Vickers indentor.

Comparatively to the value of the initial hardness of the cutting tool, the tools subjected to the treatments of coating by plasma, present a net increase in hardness. The curve, the doping is to $2.1 \%$, reveals significantly that, the evolution of the hardness depends essentially to the $\%$ of doping of iron, up to a value of saturation estimated at $2.8 \%$ of iron Figure 3 .

\subsection{Analyze Structure of Material Worked by Plasma}

The microstructure of coatings deposed on $\mathrm{NaCl}$ was observed in transmission electron microscope (MET).

Figure 4 show an analysis by STEM equipped with a system of analysis EDAX, of a layer of TiN-Fe (120.000), were obtained. For more investigation, images bottom in clearly and in black bottom were taken Figure 5. The

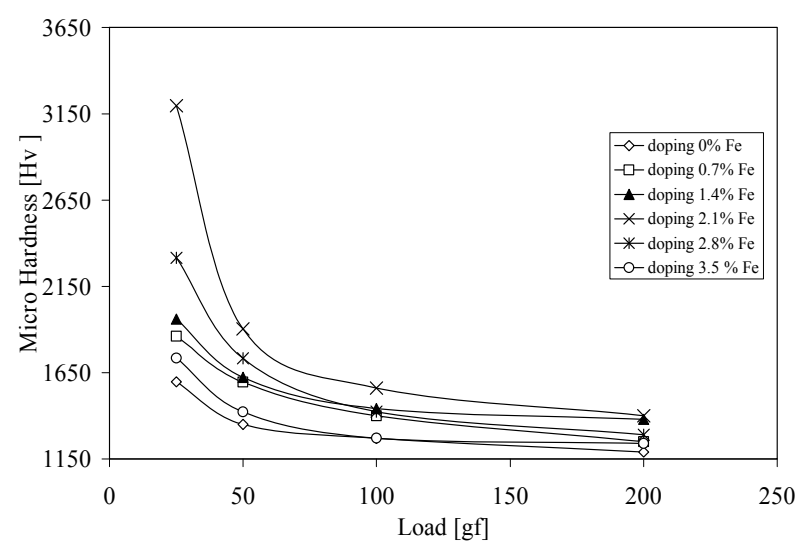

Figure 3. Micro-hardness obtained with coating Titanium nitrite.

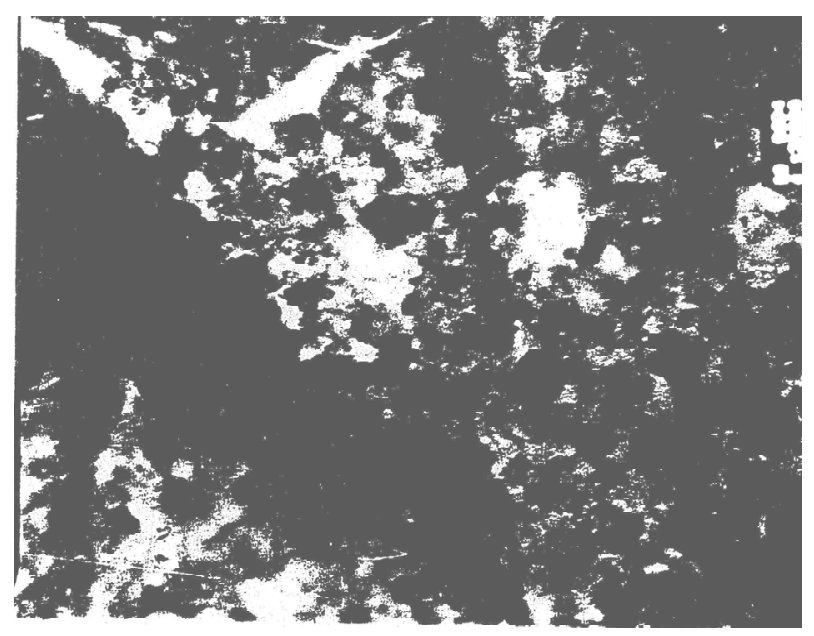

Figure 4. Micrographic in MET of one TiN-Fe layer. image in bottom black shown in Figure 6 confirms the existence of a kind of black precipitate at black spots form within the clear phase.

An electronic diagram of diffraction on the precipitate$\mathrm{p}$-was realized Figure 7. The conclusions obtained of

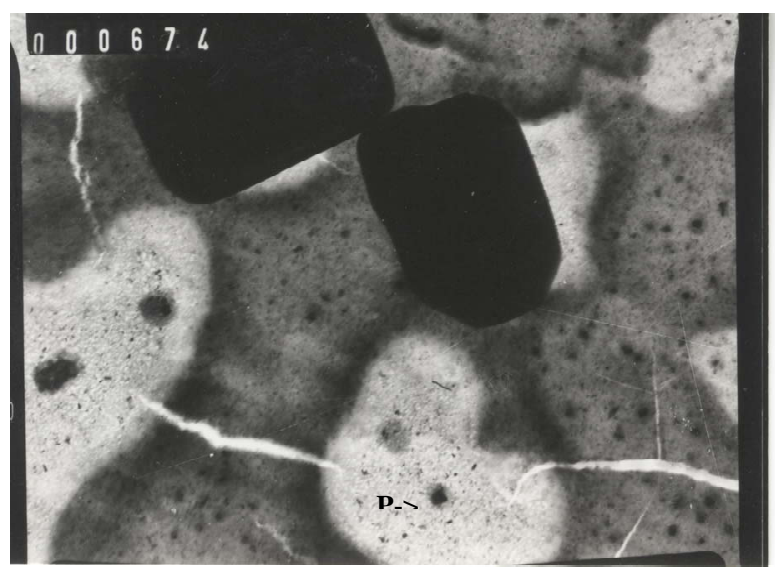

Figure 5. Image structure (background in black).

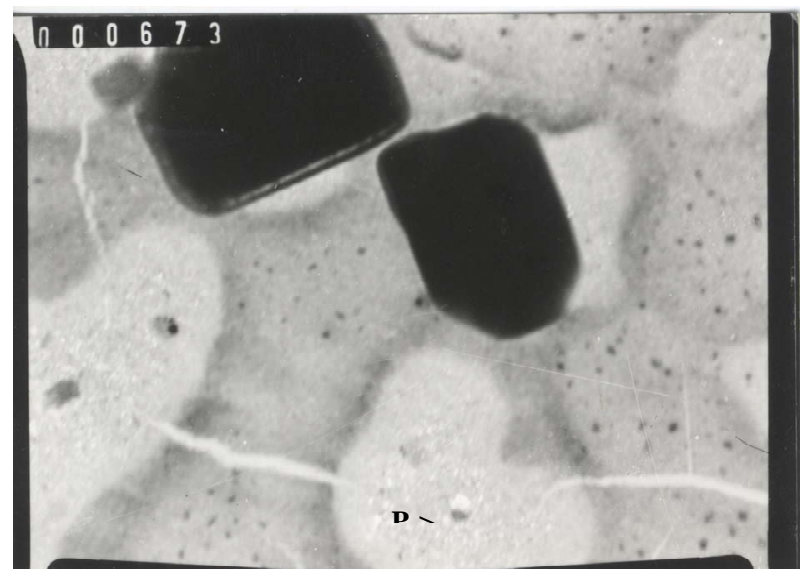

Figure 6. Image structure (background in clear).

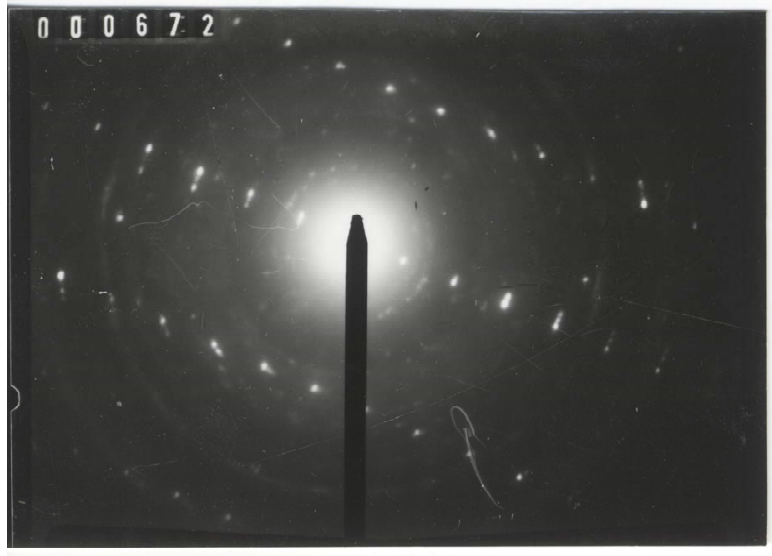

Figure 7. Electronic diffraction diagram of the precipitate: $p$. 
these analyses, support the alternative of a probability, that, iron is in the solid solution or in the form of very fine precipitates in the matrix.

\subsection{Evaluation of the Wear $\mathrm{Vb}(\mathrm{mm})$}

At the time of their submission at the machining on lathe, the cutting tools treated by plasma have a good behavior at wear.

The tests of machining on lathe EMCO, realized in agreement with the parameters of cut, such as they are defined by the standard ISO [11], and are based on the laws of the mathematical models governing the study of the lifespan from the cutting tools, show a remarkable improvement of the tribological process of the tool and the piece to machining.

The evolution gradual from the initial endurance of the tools without coating (Figure 8) shows an improvement of the endurance. The curves obtained in the stadium of low and average speeds, present a collective displacement $\mathrm{Vb}=\mathrm{f}(\mathrm{T})$ curves towards the line, which, explains the considerable reduction of the effect of the wear of the

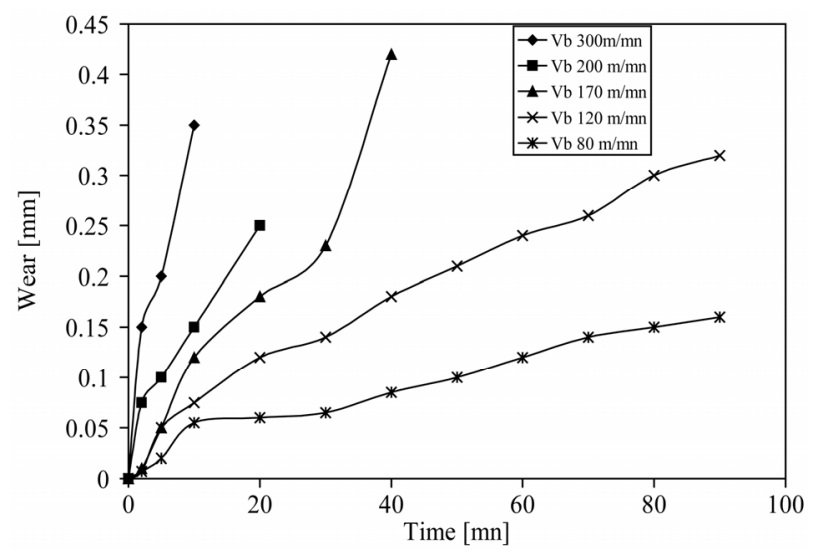

Figure 8. Curves of wear of tool without plasma treatment for the different speeds.

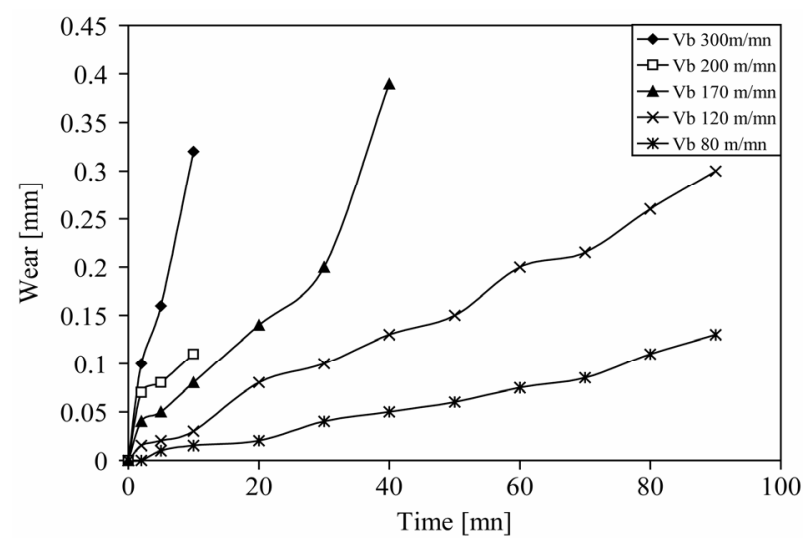

Figure 9. Curves of wear of tool with doped at $2.1 \%$ iron, for the different speeds.

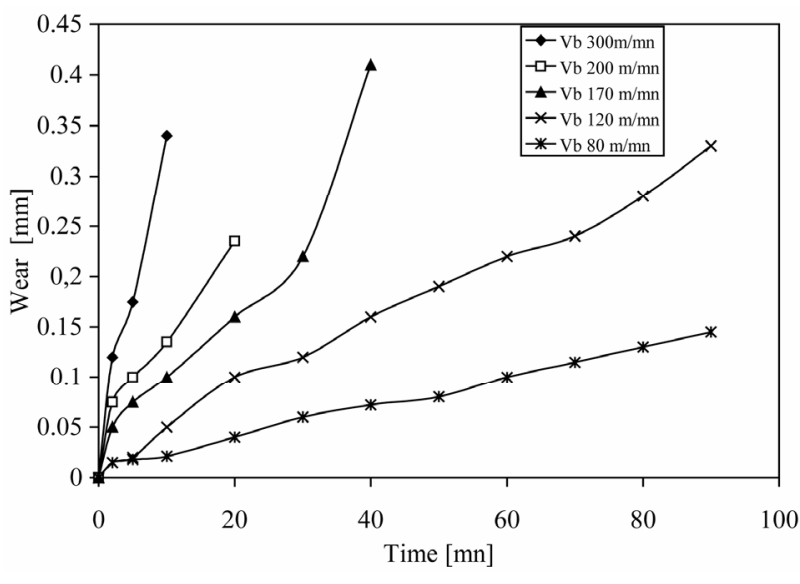

Figure 10. Curves of wear of tools with doped at $2.8 \%$ iron for the different speeds.

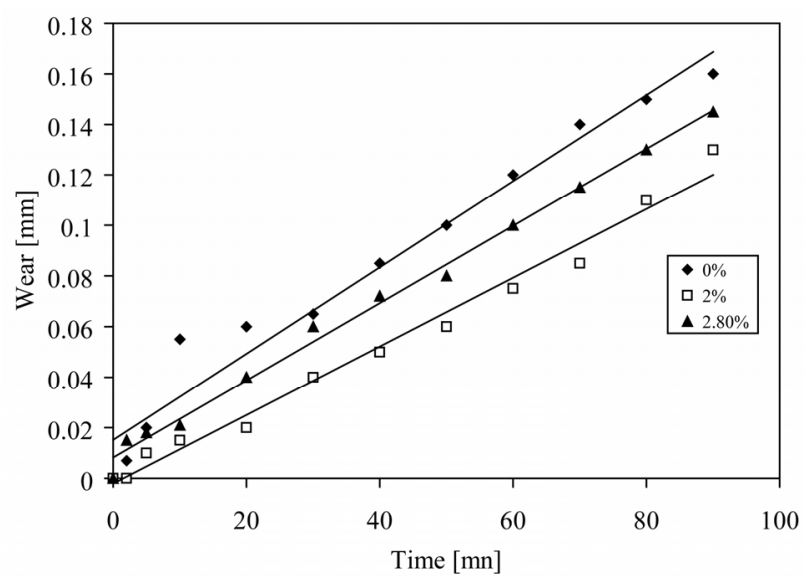

Figure 11. Comparison of wear of tool with doped at $0 \%$, $2.1 \%$ and $2.8 \%$ iron for speed $V=80 \mathrm{~m} / \mathrm{mn}$.

cutting tools. One records during the machining operation a decreasing evolution of wear. The minimal value of $\mathrm{Vb}$ carried, is found with the doping of $2.1 \%$ iron (Figures 9-10) show a decreasing evolution of wear after saturation at $2.8 \%$ iron. At the Figure 11, curve at first position ( $2.1 \%$ iron) show a net improvement of wear.

\section{Conclusions}

The study of the influence of the effects of the technique of plasmas as physical phenomenon of the ionization of gases under the effect of an electric field for making a material of titanium nitride coating doped at the different percentages of iron, on the mechanical properties of the cutting tools, subjected to the hardness tests, and after for the works on lathe, shows that the contribution of these coatings obtained by plasma, improves considerably the principal mechanical characteristics of the cutting tools.

The evolution of the hardness as recorded on the curves, show a net improvement of the initial hardness of the cutting tool (basic heat treatment), also show a rise of the 
hardness of this material, obtained by plasma.

That starting from the doping of $0.7 \%$ of iron, $1.4 \%$, to reach a maximum (peak) of hardness to $2.1 \%$ of iron. At the end, one records a reduction in this same hardness starting at $2.8 \%$ of iron. This increase in hardness is the consequence of a whole of phenomena certainly related to the bombardment of the layers during their growth, as well as the mechanisms leading to the increase in the yield stress. In the case of the titanium nitride coatings, the analyses carried suppose the formation of very strong distortions of the crystal lattice. one can however think that it is the existence of these distortions (micro-deformations) which is at the origin of the increase in the yield stress, which leads to the hardening of these layers deposited (physical phenomenon of hardness).

In addition, like the phase of titanium nitrides (Chock) the structure $\mathrm{NaCl}$ [12] has, gradual evolution of hardness and its relapse with a percentage of doping equal to $2.8 \%$ of iron, can be explained by the phenomenon of saturation according to the various percentages of iron doping of the crystalline structure in sites of substitution or insertion. Concerning this structure, it was observed that the addition of iron to the TiN during the deposition by plasma appreciably increases the hardness of the layers deposited.

This increase of the hardness [13] generates an improvement of the principal mechanical characteristics, in particular the friction resistance. This aptitude of materials for the friction resistance in the field of mechanics in means of working tools, is exploited in term of wear resistance, from where improvement of the endurance and the lifespan of the cutting tools. In the extreme connection with the results of the hardness obtained, the comparative study of the tests of machining by turning, obtained with various percentages of doping of iron, show a net improvement of the longevity of the working life of the cutting tools. This variation compared with the initial tools (without coatings and doping), is characterized according to two stadiums selective of speed of machining.

During these tests of turning carried according to the law of Taylor, and in accordance with the conditions of standard ISO 3685, the curves obtained in the stadium of low and average speeds, present a collective displacement $\mathrm{Vb}=\mathrm{f}(\mathrm{T})$ curves towards the line, which, explains the considerable reduction of the effect of the wear of the cutting tools. One records during the machining operation a decreasing evolution of wear. The minimal value of $\mathrm{Vb}$ carried, is found with the doping of $2.1 \%$ iron.

\section{Acknowledgements}

The authors would like to acknowledge the encouragement and support of this research by Professor Achour S. Research Unit in Materials Physics and Applications, University of Constantine, Algeria.

\section{REFERENCES}

[1] J. L. Vossen and W. Kern, "Chock Film Processes Edit," Academic Press, Cambridge.

[2] R. Wei, "Plasma Enhanced Magnetron Sputter Deposition of Ti-Si-C-N Based Nanocomposite Coatings," Surface and Coatings Technology, Vol. 203, No. 5-7, 2008, pp. 538-544.

[3] F. Kieckow, C. Kwietniewski, E. K. Tentardini, A. Reguly and I. J. R. Baumvol, "XPS and Ion Scattering Studies on Compound Formation and Interfacial Mixing in TiN/Ti Nanolayers on Plasma Nitrided Tool Steel," Surface and Coatings Technology, Vol. 201, No. 6, 2006, pp. 3066-3073. doi:10.1016/j.surfcoat.2006.06.020

[4] S. Cardinal, A. Malchère, V. Garnier and G. Fantozzi "Microstructure and Mechanical Properties of TiC-TiN Based Cermets for Tools Application," International Journal of Refractory Metals \& Hard Materials, Vol. 27. No. 3, 2009, pp. 521-527.

[5] B. Subramanian, K. Ashok and M. Jayachandran, "Effect of Substrate Temperature on the Structural Properties of Magnetron Sputtered Titanium Nitride Thin Films with Brush Plated Nickel Interlayer on Mild Steel," Applied Surface Science, Vol. 255, No. 5, 2008, pp. 2133-2138.

[6] Y. K. Jeong, M. C. Kang, S. H. Kwon, K. H. Kim, H. G. Kim and J. S. Kim, "Tool Life of Nanocomposite TiAl-Si-N Coated End-Mill by Hybrid Coating System in High Speed Machining of Hardened AISI D2 Steel," Current Applied Physics, Vol. 9, No. 1, Supplement 1, 2009, pp. S141-S144.

[7] A. Ebrahimi and M. M. Moshksar, "Evaluation of Machinability in Turning of Microalloyed and Quenchedtempered Steels: Tool Wear, Statistical Analysis, Chip Morphology," Journal of Materials Processing Technology, Vol. 209, No. 2, 19, 2009, pp. 910-921. doi:10.1016/j.jmatprotec.2008.02.067

[8] M. A. Yallese, K. Chaoui, N. Zeghib, L. Boulanouar and J. F. Rigal, "Hard Machining of Hardened Bearing Steel Using Cubic Boron Nitride Tool," Journal of Materials Processing Technology, Vol. 209, No. 2, 2009, pp. 10921104. doi:10.1016/j.jmatprotec.2008.03.014

[9] E. Fergag, S. Achour, A. Harabi and K. Mirouh, "Iron doped Titanium Nitride Film," Ceramic Processing Science and Technology (Ceramic Transactions, Vol. 51), International Conference on Ceramic Processing Science and Technology, April 1995, pp. 789-792.

[10] E. Fergag, "Realization of One System of Pulverization Magnetron," Application to titanium Nitrides, Magister Thesis, University of Constantine, Constantine, 1994.

[11] Development of the Standards, ISO 3685, Tests life of the shaper tools to active part. International Standard. www.upcomillas.es/periodicas

[12] J. E. Sundgren, "Structure and Properties of TIN Coatings," Thin Solid Films, Vol. 128, No. 1-2, 1985, pp. 21-44.

[13] W. D. Sproul, "Very High Rate Reactive Sputtering of TiN, ZrN and HfN," Thin Solid Films, Vol. 107, No. 2, 1983, pp. 141-147. doi:10.1016/0040-6090(83)90016-0 